\title{
Insulin Resistance in Liver Cirrhosis \\ Positron-emission Tomography Scan Analysis of Skeletal Muscle Glucose Metabolism
}

\author{
Oliver Selberg, Wolfgang Burchert, ${ }^{\star}$ Jörg v. d. Hoff,“ Geerd J. Meyer, " Heinz Hundeshagen, \\ Eva Radoch, Hans-Joachim Balks, ${ }^{\star}$ and Manfred J. Müller \\ Zentrum Innere Medizin und Dermatologie, Abteilung Gastroenterologie und Hepatologie, *Abteilung für Nuklearmedizin, \\ and ${ }^{\ddagger}$ Abteilung für Endokrinologie, Medizinische Hochschule Hannover, D-3000 Hannover 61, Germany
}

\begin{abstract}
Background. Insulin resistance and glucose intolerance are a major feature of patients with liver cirrhosis. However, site and mechanism of insulin resistance in cirrhosis are unknown. We investigated insulin-induced glucose metabolism of skeletal muscle by positron-emission tomography to identify possible defects of muscle glucose metabolism in these patients.

Methods. Whole body glucose disposal and oxidation were determined by the combined use of the euglycemic-hyperinsulinemic clamp technique (insulin infusion rate: $1 \mathrm{mU} / \mathrm{kg}$ body wt per min) and indirect calorimetry in seven patients with biopsy-proven liver cirrhosis (Child: 1A, 5B, and 1C) and five healthy volunteers. Muscle glucose uptake of the thighs was measured simultaneously by dynamic $\left[{ }^{18} \mathrm{~F}\right]$ fluorodesoxyglucose positron-emission tomography scan.
\end{abstract}

Results. Both whole body and nonoxidative glucose disposal were significantly reduced in patients with liver cirrhosis (by 48\%, $P<0.001$, and 79\%, $P<0.0001$, respectively), whereas glucose oxidation and the increase in plasma lactate were normal. Concomitantly, skeletal muscle glucose uptake was reduced by $69 \%$ in liver cirrhosis $(P<0.003)$ and explained 55 or 92\% of whole body glucose disposal in cirrhotics and controls, respectively. Analysis of kinetic constants using a three-compartment model further indicated reduced glucose transport $(P$ $<0.05$ ) but unchanged phosphorylation of glucose in patients with liver cirrhosis.

Conclusions. Patients with liver cirrhosis show significant insulin resistance that is characterized by both decreased glucose transport and decreased nonoxidative glucose metabolism in skeletal muscle. (J. Clin. Invest. 1993.91:1897-1902.) Key words: insulin-clamp $\cdot\left[{ }^{18} \mathrm{~F}\right]$ fluorodesoxyglucose • glucose metabolism • muscle glucose uptake • skeletal muscle

\section{Introduction}

Glucose intolerance is frequently seen in patients with chronic liver disease. Impaired hepatic glucose metabolism (i.e., diminished postprandial hepatic glucose uptake and storage as glycogen and shunting of insulin and glucose) has been sug-

Address correspondence to Dr. O. Selberg, Medizinische Hochschule Hannover, Abteilung Gastroenterologie und Hepatologie, Ernährungsmedizin und Diätetik, Konstanty-Gutschow-Strasse 8, D-3000 Hannover 61 , Germany.

Received for publication 28 August 1992 and in revised form 14 December 1992.

J. Clin. Invest.

(c) The American Society for Clinical Investigation, Inc.

0021-9738/93/05/1897/06 \$2.00

Volume 91, May 1993, 1897-1902 gested to explain most of the disturbances in glucose metabolism in cirrhosis $(1,2)$. However, the maintenance of normal glucose homeostasis depends on the coordinated response of insulin secretion, suppression of hepatic glucose production, and stimulation of hepatic and peripheral glucose uptake. Although hyperinsulinemia is frequently observed in patients with liver cirrhosis, insulin secretion was normal in most cirrhotics studies (3). Basal hepatic glucose production is also normal or reduced in patients with liver cirrhosis and suppressed to a similar degree as in control subjects in response to insulin (by 85 vs $90 \%$ (4), 97 vs $85 \%$ (5), and 95 vs $95 \%$ (6) at plasma insulin levels of 30-60 mU/liter, 80-90 mU/liter, and 40-60 mU/liter, respectively), suggesting that there is no significant hepatic insulin resistance in patients with liver cirrhosis. Little is known about hepatic glucose uptake after a glucose load in cirrhotic patients. With reference to whole body glucose utilization, most studies used the glucose clamp technique to demonstrate a reduced insulin sensitivity, as well as responsivity in patients with liver cirrhosis $(5,7,8)$. Since the insulin clamp technique has been shown to reflect primarily extrahepatic glucose metabolism (which accounts for $\sim 85 \%$ of whole body glucose metabolism during clamp conditions (9)), defective muscle glucose metabolism may be responsible for glucose intolerance in patients with liver cirrhosis. This suggestion is further supported by forearm studies that demonstrate some insulin insensitivity, i.e., decreased glucose extraction, which can be compensated for by hyperinsulinemia (10).

More recent studies combined the clamp technique with indirect calorimetry to characterize the mechanism of insulin resistance and showed that defective insulin action associated with liver cirrhosis is exclusively caused by a defect in nonoxidative glucose metabolism, whereas net increases in glucose oxidation are normal $(6,8,11)$. Using pharmacological amounts of insulin increases of nonoxidative glucose disposal are accompanied by increased anaerobic glycolysis; i.e., a disproportionate increase in plasma lactate concentrations (11). Similarly, the activation of muscle glycogen synthase as well as the increase in muscle glycogen content during an insulin clamp protocol were reduced in patients with liver cirrhosis (12). However, since precise studies of muscle glucose metabolism are lacking, we directly assessed skeletal muscle glucose metabolism in vivo. In this study, we applied for the first time dynamic positron-emission tomography (PET $)^{1}$ scan analysis using the FDG model for quantitation of skeletal muscle glucose uptake as well as the kinetic constants of glucose transport and phosphorylation in man. We combined the clamp tech-

1. Abbreviations used in this paper: AMA, arm muscle area; FDG, fluorodeoxyglucose; HGP, hepatic glucose production; MAC, midarm circumference; PET, positron-emission tomography; TSF, triceps skin fold thickness. 
Table I. Physical Characteristics of Patients and Controls

\begin{tabular}{|c|c|c|c|c|c|c|c|}
\hline & Age & Sex & Weight & Height & TSF & MAC & Crea* \\
\hline & $y r$ & & $k g$ & $\mathrm{~cm}$ & $m m$ & $\mathrm{~cm}$ & $\mathrm{mmol} / \mathrm{d}$ \\
\hline \multicolumn{8}{|l|}{ Patients } \\
\hline Mean \pm SEM & $44 \pm 6^{\ddagger}$ & 5 female $/ 2$ male & $62 \pm 5$ & $166 \pm 4^{\ddagger}$ & $9 \pm 2$ & $25.6 \pm 1.8$ & $9.2 \pm 1.2^{\ddagger}$ \\
\hline \multicolumn{8}{|l|}{ Controls } \\
\hline Mean \pm SEM & $27 \pm 3$ & 1 female $/ 4$ male & $74 \pm 4$ & $182 \pm 3$ & $10 \pm 2$ & $28.4 \pm 0.5$ & $17.0 \pm 1.1$ \\
\hline Normal Range & & & & & $4.0-25.0$ & $23.5-32.6$ & $7.2-20.7$ \\
\hline
\end{tabular}

* Urinary creatinine excretion, ${ }^{\ddagger} P<0.05$ vs controls.

nique with indirect calorimetry plus dynamic PET scan analysis to assess the extent to which defects in skeletal muscle glucose metabolism account for insulin resistance in patients with liver cirrhosis.

\section{Methods}

Subjects. Seven patients (ci) with biopsy-proven liver cirrhosis (three postnecrotic, one ethanol induced, two biliary, and one cryptogenic) were compared with five healthy volunteers ( $\mathrm{Co}$ ) whose physical characteristics are presented in Table I. Following serum concentrations were observed in the patient group (mean \pm SEM): serum glutamate oxaloacetate transaminase, $44 \pm 9 \mathrm{U} /$ liter; bilirubin, $81 \pm 28 \mu \mathrm{mol} / \mathrm{liter}$; albumin, $27 \pm 2 \mathrm{~g} /$ liter; and methionine, $78 \pm 18 \mu \mathrm{mol} /$ liter. All control subjects were in good health, none had taken any medication in the week before or during the study, and none had a history of endocrine disease. Clinical classification was based on the plasma concentrations of bilirubin, albumin, and the prothrombin time, as well as the occurrence of ascites and encephalopathy (i.e., Child-Pugh score, reference 13). Patients and control subjects were informed of the nature, purpose, and possible risk of the study and gave informed written consent before the start of the study. The protocol had been reviewed and approved by the Ethical Committee of the Medizinische Hochschule Hannover (Hannover, Germany).

Body composition analysis. Body composition analysis included anthropomorphometrics (triceps skin fold thickness [TSF] midarm circumference [MAC]) and 24-h urinary creatinine excretion. Whole body muscle mass was calculated from arm muscle area $(A M A$ $=[M A C-\pi \cdot T S F]^{2} / 4 \pi-z$, where $z=10.0$ for males and $z=6.5$ for females) according to Heymsfield (muscle mass $=$ height $\cdot[0.0264$ +0.0029 - AMA ]; reference 14) and from creatinine excretion assuming that $1 \mathrm{~g}$ creatinine $=18.5 \mathrm{~kg}$ muscle $(15)$.

Experimental design. The study protocol is given in Fig. 1. Two peripheral venous catheters were inserted, one into an antecubital vein for the infusion of test substances (Venflon 2; Viggo, Helsingborg, Sweden), and the other retrogradely into a wrist vein for blood sampling (Butterfly; Abbott, Sligo, Ireland). Both were kept open by infusing a minimal amount of $0.9 \%$ saline. The hand was then placed in a box heated at $50-60^{\circ} \mathrm{C}$ to achieve arterialization of the blood. The subjects

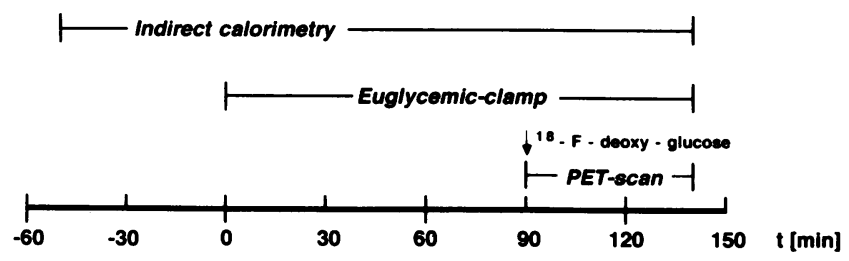

Figure 1. Study protocol. were asked to remain motionless and awake and were allowed $30 \mathrm{~min}$ to equilibrate to the environment.

Respiratory gas exchange measurements were performed using a ventilated hood open circuit indirect calorimeter (Deltatrac Metabolic Monitor; Datex Instruments, Helsinki, Finland). Calibrations were done immediately before and at the end of the measurements. Gas exchange analysis was started at $-50 \mathrm{~min}$ and continued until the end of the study at $+140 \mathrm{~min}$; an euglycemic clamp (insulin infusion rate 1 $\mathrm{mU} / \mathrm{kg}$ body wt per $\mathrm{min}$ ) was performed as previously described (8) from 0 to $140 \mathrm{~min}$ and a slow bolus of $370 \mathrm{MBq}$ of $\left[{ }^{18} \mathrm{~F}\right]$ fluorodesoxyglucose (18-FDG) was injected intravenously at +90 min. Arterialized venous blood samples were taken at basal and after 120 , 130 , and $140 \mathrm{~min}$ for determination of the serum or plasma concentrations of insulin, lactate, and urea.

Analyses. Plasma glucose, serum insulin, plasma lactate, FFA, and glycerol concentrations were determined by standard in house methods as previously described $(8,11)$.

Data analyses. Indirect calorimetry data were calculated as mean values during the last $30 \mathrm{~min}$ of both periods: basal $-30-0 \mathrm{~min}$ and clamp 110-140 min. Substrate oxidation rates were calculated according to previously published methods (16). Protein oxidation was calculated from urinary urea excretion after correction for changes in the urea pool (17). The amount of glucose metabolized (glucose disposal) during the clamp protocol was calculated from the glucose infusion rate after correction for changes in the glucose space (18). Glucose oxidation was calculated from respiratory exchange data, and nonoxidative glucose metabolism was taken as the difference between glucose disposal and glucose oxidation.

Calculation of whole body and nonoxidative glucose disposal is based on the assumption that endogenous glucose production is negligible during clamp conditions. It has been shown that hepatic glucose production (HGP) is suppressed to the same extent in normal subjects and patients with liver cirrhosis (see Introduction). Moreover, the levels of hyperinsulinemia achieved in the present study are sufficient to effectively decrease hepatic HGP to negligible values $(4,6)$. HGP was not measured in this study, but even a completely shut off HGP in the control subjects and a residual HGP of $\sim 2.6 \mu \mathrm{mol} / \mathrm{kg}$ per min in the patient group, as suggested by one study (5), would not affect any of the conclusions reached in this study. All data are presented as mean \pm SD if not indicated otherwise.

Positron-emission tomography. Patients were positioned with the mid of the thighs in the center of the field of view of the scanner. Positron emission tomography was carried out using a Siemens ECAT $951 / 31$ system with a spatial resolution of $\sim 5 \mathrm{~mm}$ full width of half maximum axial and transaxial, and an axial field view of $10.4 \mathrm{~cm} .370$ MBq of 18-FDG were prepared in $10 \mathrm{ml}$ Sörensen phosphate buffer according to the recommendations by Coenen et al. (19) and injected intravenously as a slow bolus over $30 \mathrm{~s}$. 31 transaxial slices were recorded simultaneously from +90 to $+140 \mathrm{~min}$. The frame rate was six times $20 \mathrm{~s}$, three times $60 \mathrm{~s}$, two times $150 \mathrm{~s}$, two times $300 \mathrm{~s}$, and three times $600 \mathrm{~s}$. Arterialized blood samples were taken at midframe time and the activity was measured in a calibrated well counter. 


\begin{tabular}{|c|c|c|c|c|c|c|c|c|}
\hline & \multicolumn{2}{|c|}{ Glucose } & \multicolumn{2}{|c|}{ Insulin } & \multicolumn{2}{|c|}{ Glc-Ox* } & \multirow{2}{*}{$\frac{\text { Glc-M }^{\ddagger}}{\text { Clamp }}$} & \multirow{2}{*}{$\frac{\text { Glc-non-ox }}{\text { Clamp }}$} \\
\hline & Basal & Clamp & Basal & Clamp & Basal & Clamp & & \\
\hline & \multicolumn{2}{|c|}{$\mathrm{mmol} / \mathrm{liter}$} & \multicolumn{2}{|c|}{ mU/liter } & \multicolumn{2}{|c|}{$\mu \mathrm{mol} / \mathrm{kg}$ per $\min$} & $\mu \mathrm{mol} / \mathrm{kg}$ per min & $\mu \mathrm{mol} / \mathrm{kg} \mathrm{per} \mathrm{min}$ \\
\hline \multicolumn{9}{|l|}{ Patients } \\
\hline Mean & 5.12 & 5.11 & $15^{4}$ & $67^{\|}$ & 6.3 & $15.6^{11}$ & $22.2^{1}$ & $6.6^{1}$ \\
\hline \pm SEM & 0.30 & 0.24 & 2 & 9 & 1.5 & 1.9 & 2.6 & 2.1 \\
\hline \multicolumn{9}{|l|}{ Controls } \\
\hline Mean & 5.01 & 5.20 & 7 & $59^{\| \prime}$ & 3.5 & $14.9^{\prime \prime}$ & 45.4 & 30.5 \\
\hline \pm SEM & 0.18 & 0.22 & 1 & 8 & 1.5 & 2.2 & 4.9 & 4.5 \\
\hline
\end{tabular}

* Glucose oxidation rate; ${ }^{\ddagger}$ whole body glucose disposal; ${ }^{\S}$ nonoxidative glucose disposal; $P<0.05$; " clamp vs basal; ' patients vs controls.

Quantitation of muscle glucose utilization was done with the graphical Gjedde-Patlak-Plot analysis (20). Regions of interest were placed over the cross section of the thigh avoiding the vascular and bone area. To determine local transport constants, a nonlinear least squares fit of a three-constant compartment model $\left(k_{4}=0\right)$ of FDG using a lumped constant of 0.67 was performed (21). $k_{1}$ refers to the transport constant for glucose from the vascular compartment to the muscular tissue compartment, $k_{2}$ refers to the efflux of glucose from muscle tissue to the vascular compartment, and $k_{3}$ indicates the kinetic constant for irreversible intracellular phosphorylation. For investigations lasting $<60$ $\min k_{4}$ is assumed 0 as phosphorylated 18-FDG is not further metabolized to any appreciable extent (22). Regarding the physiological significance of the calculated transport constants, one has to consider that a three-compartmental approach was used: the first compartment indicating the vascular space, the second compartment representing the interstitial and free intracellular glucose space, and the third compartment referring to the intracellular pool of fixed glucose. The calculation
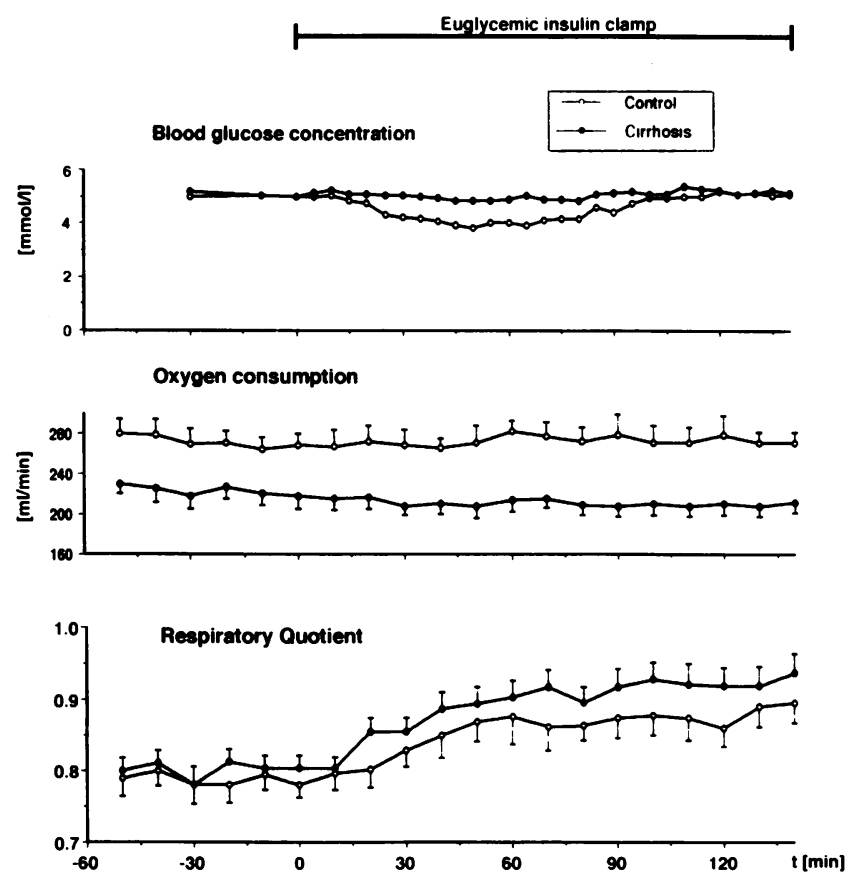

Figure 2. Basal ( $-50-0 \mathrm{~min})$ and clamp data (0-140 $\mathrm{min}$ ) of blood glucose concentrations, oxygen consumption, and respiratory quotients of patients and control subjects. Data are given as mean \pm SEM (no deviations are given for glucose). of a kinetic constant $\left(k_{2}\right)$ for the transport out of muscle tissue reflects a net effect of glucose transport across the capillary membrane, interstitial fluid and/or cellular compartments, and cannot be attributed to a single defined process like glucose transport out of muscle cells.

\section{Results}

Basal $\mathrm{VO}_{2}$ was $215 \pm 34 \mathrm{ml} / \mathrm{min}$ for the patient group (ci) and $267 \pm 29 \mathrm{ml} / \mathrm{min}$ for the control group (co); basal respiratory quotient was $0.80 \pm 0.05$ and $0.79 \pm 0.05$, respectively. During euglycemic clamp conditions, plasma glucose concentrations (Table II), $\mathrm{VO}_{2}$ (ci, $204 \pm 30 \mathrm{ml} / \mathrm{min}$; and co, $271 \pm 23 \mathrm{ml} /$ $\mathrm{min}$ ) and energy expenditure (ci: basal, 1,482 $\pm 218 \mathrm{kcal} / \mathrm{d}$, $100.4 \pm 2.3 \%$ Harris-Benedict prediction [HB] (23); clamp, $1,456 \pm 210 \mathrm{kcal} / \mathrm{d}, 103.8 \pm 9.3 \% \mathrm{HB}$; co: basal, $1,784 \pm 142$ $\mathrm{kcal} / \mathrm{d}, 100.4 \pm 2.3 \% \mathrm{HB}$; clamp, 1,864 $\pm 123 \mathrm{kcal} / \mathrm{d}, 104.9 \%$ $\mathrm{HB}$ ) remained unchanged (Fig. 2). Insulin infusion increased plasma lactate (ci: basal, $1.38 \pm 0.37 \mathrm{mmol} /$ liter; clamp, $1.64 \pm 0.44 \mathrm{mmol} /$ liter, NS; co: basal, $0.99 \pm 0.24 \mathrm{mmol} /$ liter; clamp, $1.45 \pm 0.38 \mathrm{mmol} /$ liter, $P<0.05$ ) and decreased plasma c-peptide concentrations (ci: basal, $3.21 \pm 1.74 \mathrm{ng} / \mathrm{ml}$; clamp, $2.25 \pm 1.16 \mathrm{ng} / \mathrm{ml}, P<0.05$; co: basal, $1.62 \pm 0.33 \mathrm{ng} / \mathrm{ml}$; clamp, $1.00 \pm 0.36 \mathrm{ng} / \mathrm{ml}, P<0.05)$. Whole body glucose disposal and nonoxidative glucose disposal (Table II) as well as skeletal muscle glucose uptake (Table III) were significantly reduced in the patient group. In all patients and control subjects muscle glucose uptake was similar in both thighs (Table III). Muscle mass was calculated from creatinine excretion ( $\mathrm{ci}$, $19.3 \pm 6.5 \mathrm{~kg}$; co, $35.5 \pm 5.1 \mathrm{~kg} ; P<0.001$ ) and from anthropometric data (ci, $21.4 \pm 9.6 \mathrm{~kg}$; co, $27.0 \pm 2.6 \mathrm{~kg}$, NS).

Whole body glucose uptake calculated from muscle glucose uptake times whole body muscle mass correlated significantly with whole body glucose disposal as calculated from clamp data for both the anthropometric $(r=0.912, P<0.0001)$ and the creatinine ( $r=0.893, P<0.0001)$ approach. The contribution of whole body muscle glucose uptake to whole body glucose disposal as calculated from anthropometric data was $55 \pm 22$ and $92 \pm 25 \%$ in cirrhotics and controls, respectively.

The kinetic constants for glucose transport into muscle tissue $\left(k_{1}\right)$ are decreased, for transport out of muscle tissue $\left(k_{2}\right)$ are increased, and glucose phosphorylation is concomitantly unchanged in patients with liver cirrhosis (Table III). Decreased accumulation of muscle tissue 18-FDG activity during euglycemic clamp conditions was clearly identified in patients 
Table III. Muscle Glucose Uptake and Kinetic Constants of Muscle Glucose Transport

\begin{tabular}{|c|c|c|c|c|c|}
\hline & \multirow[b]{2}{*}{$K_{1}$} & \multirow[b]{2}{*}{$K_{2}$} & \multirow[b]{2}{*}{$K_{3}$} & \multicolumn{2}{|c|}{$\begin{array}{l}\text { Muscle glucose } \\
\text { uptake }\end{array}$} \\
\hline & & & & $\begin{array}{l}\text { Right } \\
\text { thigh }\end{array}$ & $\begin{array}{l}\text { Left } \\
\text { thigh }\end{array}$ \\
\hline & $1 / \min$ & $1 / \min$ & $1 / \min$ & $\mu \mathrm{mol} / \mathrm{l}$ & per min \\
\hline \multicolumn{6}{|l|}{ Patients } \\
\hline 1 & 0.0288 & 0.0545 & 0.0158 & 4.49 & 4.29 \\
\hline 2 & 0.0180 & 0.0428 & 0.0220 & 3.87 & 3.85 \\
\hline 3 & 0.0168 & 0.0197 & 0.0134 & 4.81 & 4.98 \\
\hline 4 & 0.0154 & 0.0432 & 0.0212 & 3.23 & 3.57 \\
\hline 5 & 0.0163 & 0.0475 & 0.0206 & 2.92 & 3.06 \\
\hline 6 & 0.0134 & 0.0495 & 0.0186 & 1.79 & 1.81 \\
\hline 7 & 0.0178 & 0.0466 & 0.0167 & 3.05 & 2.80 \\
\hline Mean & $0.0181^{*}$ & $0.0434^{*}$ & 0.0183 & $3.45^{*}$ & $3.48^{*}$ \\
\hline \pm SEM & 0.0019 & 0.0042 & 0.0012 & 0.39 & 0.39 \\
\hline \multicolumn{6}{|l|}{ Controls } \\
\hline Mean & 0.0357 & 0.0288 & 0.0267 & 11.49 & 12.07 \\
\hline \pm SEM & 0.0083 & 0.0048 & 0.0045 & 2.40 & 2.56 \\
\hline
\end{tabular}

$* P<0.05$ patients vs controls.

with liver cirrhosis. Fig. 3 depicts a representative example of the cumulative thigh 18-FDG activity in one control person and one patient. The dynamic registration of blood and tissue 18-FDG activity (Fig. 4) further allowed quantitation of muscle glucose uptake assuming validity of the 18-FDG model for human skeletal muscle. Validation of the 18-FDG model originates from comparative studies of $18-\mathrm{FDG}$ with [ $\left.{ }^{11} \mathrm{C}\right]$ glucose in rabbit heart muscle, which indicate a correction factor ("lumped constant") of 0.67 . This value is used for most of human 18-FDG studies analyzing glucose metabolism of the heart muscle (24). Because of the metabolic similarities between heart muscle and skeletal muscle, the use of this lumped constant seems to be reasonable. The absolute value of the metabolic rate of glucose depends on the lumped constant, the determination of kinetic constants are not influenced. Furthermore, the ratio of the metabolic rates of glucose remains the same even if the absolute value is not exactly known. There is no rationale for the assumption that the lumped constant should differ in cirrhotics and noncirrhotic individuals, since the same biochemical pathways and enzymes are operative.

\section{Discussion}

This study gives evidence that skeletal muscle is the primary site of insulin resistance in patients with liver cirrhosis (Table III; Fig. 3). Application of the PET technique allowed for the first time direct in vivo evidence of diminished insulin-dependent glucose transport into skeletal muscle tissue in patients with liver cirrhosis. At the same time, glucose oxidation (as determined by indirect calorimetry) and phosphorylation are normal and whole body nonoxidative glucose disposal (i.e., glycogen synthesis; reference 25 ) is markedly depressed in these patients (Table II). The age difference between the control and the study group (Table I) may also explain a small component of the observed difference in insulin sensitivity (26).

It was recently suggested that insulin resistance in obesity and non-insulin-dependent diabetes mellitus may be explained by a decreased effect of insulin to stimulate skeletal muscle blood flow rather than impaired insulin-induced glucose transport $(27,28)$. Concerning the question of the influence of blood flow on the rate constants of the compartment model it should be stressed that changes in blood flow have no influence on these parameters as long as the changes are due to variations in the perfusion of a fixed number of capillaries of constant size. A small indirect influence on $k_{1}$ via the dependence of the extraction fraction on the blood flow amounts typically to corrections of $\leq 10 \%(29,30)$. Using this approach an explanation of the observed differences in the rate constant $k_{1}$ as a consequence of differentially induced blood flow

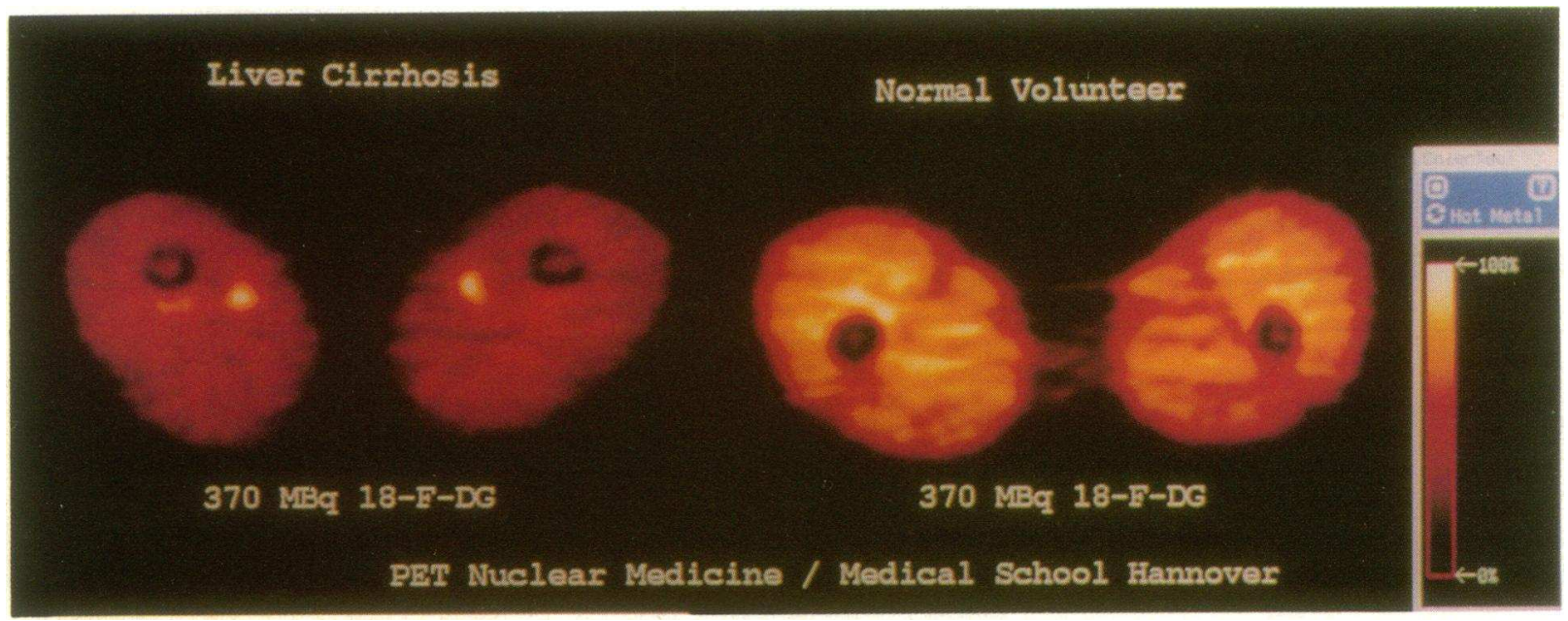

Figure 3. Representative example of cumulative thigh tissue activity during euglycemic clamp conditions (see protoeol Fig. 1) in one patient (liver cirrhosis, left side) and one control subject (normal volunteer, right side). Note that high activity is indicated by lighter colouring. In the cirrhotic patient the light areas in the middle of the thigh are blood vessels containing a relative high concentration of non-utilized labeled glucose at "late" times. 

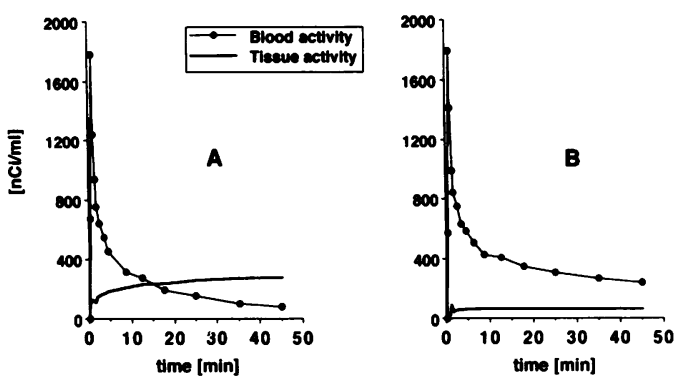

Figure 4. Representative example of time dependent blood and tissue activity in one control subject $(A)$ and one patient with liver cirrhosis $(B)$ after a bolus of $370 \mathrm{MBq}$ FDG during clamp conditions (see protocol Fig. 1).

changes is not possible. If, on the other hand there are changes in blood flow that were entirely caused by "capillary recruitment" as previously suggested (31) the parameters $k_{1}$ and $k_{2}$ would be altered by a common factor (increasing with increasing blood flow), whereas $k_{3}$ would remain constant. This statement holds true as long as the tracer in tissue distributes fast enough to prevent significant concentration gradients in the tissue space. The explanation of insulin resistance in terms of a decreased stimulation of blood flow would then be equivalent to the statement that $k_{1}$ and $k_{2}$ vary in a constant proportion between the two groups whereas $k_{3}$ remains constant. Our results do not show such a behavior: the $k_{1}$ ratio is not equal to the $k_{2}$ ratio, as can be seen from Table III. Thus, the hypothesis of impaired "capillary recruitment" as a cause of insulin resistance in patients with liver cirrhosis is not supported by our data. Instead, our PET data suggest that insulin resistance is caused mainly by alterations of the glucose transport system.

Insulin activates both glucose transport into the cell and its metabolic conversion to glycogen and $\mathrm{CO}_{2}(32)$. Experimental liver cirrhosis in rats is associated with significantly reduced whole body glucose disposal and markedly depressed glycogen formation but only marginally reduced uptake of 2-deoxyglucose by red skeletal muscle (33). In contrast, significantly lower glucose transport values of isolated adipocytes have been demonstrated in cirrhotic patients for basal and maximal insulin concentrations (5). Our PET data directly demonstrate reduced glucose transport into skeletal muscle tissue during euglycemic hyperinsulinemia. This finding, however, does not resolve the question whether a primary defect of glucose transport into skeletal muscle tissue, a primary defect of intracellular glycogen synthesis, or a combination of two independent defects is operative. Previous studies of our group using a "matched" clamp protocol in patients with liver cirrhosis (i.e., normalizing whole body glucose disposal and presumably cellular glucose [-6-phosphate] concentrations in patients with liver cirrhosis by use of pharmacological amounts of insulin) showed normal rates of nonoxidative glucose metabolism (11). Nonoxidative glucose disposal includes the conversion of glucose to glycogen, or fat, as well as anaerobic glycolysis. Because no net lipogenesis occurred during hyperinsulinemia in controls and cirrhotic patients and a disproportionate increase in anaerobic glycolysis in response to hyperinsulinemia was observed in the cirrhotic group, we take this finding as indirect evidence that at least part of impaired glycogen synthesis in liver cirrhosis is independent of the glucose transport system (11).

In conclusion, this study has shown that insulin resistance in liver cirrhosis is characterized by markedly reduced skeletal muscle glucose transport and diminished glycogen synthesis. At the same time glucose oxidation and phosphorylation appear normal.

\section{References}

1. Creutzfeld, W., H. Hartmann, M. Nauck, and F. Stöckmann. 1983. Liver disease and glucose homeostasis. In Liver in Metabolic Diseases. L. Blanchi, W. Gerok, L. Landmann, K. Sickonger, and G. A. Stalder, editors. MTP Press Ltd., Boston. 221-234.

2. Taylor, R., D. G. Johnston, and K. G. M. M. Alberti. 1986. Glucose homoiostasis in chronic liver disease. Clin. Sci. (Lond.). 70:317-320.

3. Petrides, A. S., and R. A. DeFronzo. 1989. Glucose metabolism in cirrhosis a review with some perspectives for the future. Diabetes Metab. Rev. 5:691-709.

4. Proietto, J., F. P. Alford, and F. J. Dudley. 1980. The mechanism of carbohydrate intolerance of cirrhosis. J. Clin. Endocrinol. Metab. 51:1030-1036.

5. Cavallo-Perin, P., M. Cassader, C. Bozzo, A. Bruno, P. Nuccio, A. M. Dall'Omo, M. Marucci, and G. Pagano. 1985. Mechanism of insulin resistance in liver cirrhosis. Evidence of a combined receptor and postreceptor defect. J. Clin. Invest. 75:1659-1665.

6. Petrides, A. S., L. C. Groop, C. A. Rieley, and R. A. DeFronzo. 1991. Effect of physiologic hyperinsulinemia on glucose and lipid metabolism in cirrhosis. $J$. Clin. Invest. 88:561-570.

7. Iversen, J., H. Vilstrup, and N. Tygstrup. 1984. Kinetics of glucose metabolism in relation to insulin concentrations in patients with alcoholic cirrhosis and in healthy persons. Gastroenterology. 87:1138-1143.

8. Müller, M. J., A. Fenk, H. U. Lautz, O. Selberg, H. Canzler, H. J. Balks, A. v. z. Mühlen, E. Schmidt, and F. W. Schmidt. 1991. Energy expenditure and substrate metabolism in ethanol-induced liver cirrhosis. Am. J. Physiol. 260:E338-E349.

9. DeFronzo, R. A., E. Jacot, E. Jequier, E. Maeder, J. Wahren, and J. P. Felber. 1981. The effect of insulin on the disposal of intravenous glucose. Results from indirect calorimetry and hepatic and femoral venous catheterization. Diabetes. 30:1000-1007.

10. Leatherdale, B. A., R. A. Chase, J. Rogers, K. G. M. M. Acberti, P. Davis, and C. O. Record. 1980. Forearm glucose uptake in cirrhosis and its relationship to glucose tolerance. Clin. Sci. (Lond.). 59:191-198.

11. Müller, M. J., O. Willmann, A. Rieger, A. Fenk, O. Selberg, H. U. Lautz, M. Bürger, H. J. Balks, A. v. z. Mühlen, and F. W. Schmidt. 1992. Mechanism of insulin resistance associated with liver cirrhosis. Impact of the aetiology of cirrhosis, the clinical and the nutritional state of the patients. Gastroenterology. 102:2033-2041.

12. Kruszynska, Y. N., N. Williams, M. Perry, and P. Home. 1988. The relationship between insulin sensitivity and skeletal muscle enzyme activities in liver cirrhosis. Hepatology (Baltimore). 8:1615-1619.

13. Pugh, R. N. H., I. M. Murray-Lyon, J. L. Dawson, M. C. Pietron, and R. Will. 1973. Transection of the oesophagus for bleeding of oesophageal varices. $\mathrm{Br}$. J. Surg. 60:646-649.

14. Heymsfield, S. B., C. McMannus, J. Smith, V. Stevens, and D. W. Nixo. 1982. Anthropometric measurement of muscle mass: revised equations for calculating bone-free arm muscle area. Am. J. Clin. Nutr. 36:680-690.

15. Lukaski, H. C. 1987. Methods for the assessment of human body composition: traditional and new. Am. J. Clin. Nutr. 46:537-556.

16. Jequier, E., K. Acheson, and Y. Schutz. 1987. Assessment of energy expenditure and fuel utilization in man. Annu. Rev. Nutr. 7:187-208.

17. Tappy, L., O. E. Owen, and G. Boden. 1988. Effect of hyperinsulinemia on urea pool size and substrate oxidation rates. Diabetes. 37:1212-1216.

18. DeFronzo, R. A., J. D. Tobin, and R. Andres. 1979. Glucose clamp technique: a method for quantifying insulin secretion and resistance. $\mathrm{Am}$. J. Physiol. 6:E214-E223.

19. Coenen, H. H., V. W. Pike, G. Stöcklin, and R. Wagner. 1987. Recommendation for a practical production of [2-18F] fluoro-2-deoxy-D-glucose. Appl. Radiat. Isot. 38:605-610.

20. Patlak, C., R. G. Blasberg, and J. D. Fenstermacher. 1983. Graphical evaluation of blood to brain transfer constants from multiple-time uptake data. $J$. Cereb. Blood Flow Metab. 6:154-169.

21. Sokoloff, L., M. Reivich, C. Kennedy, M. H. DesRosiers, C. S. Patlak, K. D. Pettigrew, O. Sakurada, and M. Shinohara. 1977. The $\left({ }^{14} \mathrm{C}\right)$ de-oxyglucose method for the measurement of local cerebral glucose utilization: theory, proce dure, and normal values in the conscious and anesthetized albino rat. J. Neuro chem. 28:897-916. 
22. Krivokapich, J., S. C. Huang, M. E. Phelps, J. R. Barrio, C. R. Watanabe, C. E. Selin, and K. I. Shine. 1982. Estimation of rabbit myocardial metabolic rate for glucose using fluorodeoxyglucose. Am. J. Physiol. 243:H884-H895.

23. Harris, J. A., and F. G. Benedict. 1919. A biometric study of basal metabolism in man. Carnegie Institute of Washington. Publication No. 279.

24. Choi, Y., R. A. Hawkins, S. C. Huang, S. S. Gambhir, R. C. Brunken, M. E. Phelps, and H. R. Schelbert. 1991. Parametric images of myocardial metabolic rate of glucose generated from dynamic cardiac PET and 2-[18-F]fluore-2deoxy-d-glucose studies. J. Nucl. Med. 32:733-738.

25. Shulman, G. I., D. L. Rothman, T. Jue, P. Stein, R. A. DeFronzo, and R. G. Shulman. 1990. Quantitation of muscle glycogen synthesis in normal subjects and subjects with non-insulin-dependent diabetes by ${ }^{13} \mathrm{C}$ nuclear magnetic resonance spectroscopy. N. Engl. J. Med. 322:223-228.

26. Rowe, J. W., K. L. Minaker, J. A. Pallotta, and J. S. Flier. 1983. Characterization of the Insulin Resistance of Aging. J. Clin. Invest. 71:1581-1587.

27. Laakso, M., S. V. Edelman, G. Brechtel, and A. D. Baron. 1990. Decreased effect of insulin to stimulate skeletal muscle blood flow in obese man. A novel mechanism for insulin resistance. J. Clin. Invest. 85:1844-1852.

28. Baron, A. D., M. Laakso, G. Brechtel, B. Hoit, C. Watt, and S. V. Edel- man. 1990. Reduced postprandial skeletal muscle blood flow contributes to glucose intolerance in human obesity. J. Clin. Endocrinol. \& Metab. 70:1525-1533.

29. Kelley, D., A. Mitrakou, H. Marsh, F. Schwenk, J. Benn, G. Sonnenberg, M. Arcangeli, T. Aoki, J. Sorensen, M. Berger et al. 1988. Skeletal muscle glycolysis, oxidation, and storage of an oral glucose load. J. Clin. Invest. 81:1563-1571.

30. Jackson, R. A., R. D. Roshania, M. I. Hawa, B. M. Sim, and L. DiSilvio. 1986. Impact of glucose ingestion on hepatic and peripheral glucose metabolism in man: an analysis based on simultaneous use of the forearm and double isotope techniques. J. Clin. Endocrinol. \& Metab. 63:541-549.

31. Baron, A. D., M. Laakso, G. Brechtel, and S. V. Edelman. 1991. Mechanism of insulin resistance in insulin dependent diabetes mellitus: a major role for reduced skeletal muscle blood flow. J. Clin. Endocrinol. \& Metab. 73:637-643.

32. Bogardus, C., S. Lillioja, K. Stone, and D. Mott. 1984. Correlation between muscle glycogen synthase activity and in vivo insulin action in man. $J$. Clin. Invest. 73:1185-1190.

33. Meyer-Alber, A., H. Hartmann, F. Stümpel, and W. Creutzfeldt. 1992. Mechanism of insulin resistance in $\mathrm{CCl}_{4}$-induced cirrhosis of rats. Gastroenterology. 102:223-229. 